Ethier Isabelle (Orcid ID: 0000-0003-4909-0417)

Davies Christopher (Orcid ID: 0000-0001-6595-8656)

Roberts Matthew (Orcid ID: 0000-0003-1665-3455)

See Emily (Orcid ID: 0000-0003-4436-4319)

\title{
Variability and trends over time and across centres in haemodialysis weekly duration in Australia and New Zealand
}

\author{
Isabelle Ethier ${ }^{1,2}$ \\ Yeoungjee $\mathrm{Cho}^{2,3,4}$ \\ Christopher E Davies 3,5 \\ Carmel M Hawley $2,3,4,6$ \\ Scott B Campbell ${ }^{2}$ \\ Nicole M Isbel 2,4 \\ Elaine M Pascoe ${ }^{4,7}$ \\ Kevan R Polkinghorne $8,9,10$ \\ Matthew Roberts ${ }^{11}$ \\ Emily J See ${ }^{12,13}$ \\ David Semple 14,15 \\ Carolyn van $\mathrm{Eps}^{2}$ \\ Andrea K Viecelli2,4 \\ David W Johnson $2,3,4,6$ \\ ${ }^{1}$ Division of Nephrology, Centre Hospitalier de I'Université de Montréal, Montréal, Canada \\ ${ }^{2}$ Department of Nephrology, Princess Alexandra Hospital, Brisbane, Australia \\ ${ }^{3}$ Australia and New Zealand Dialysis and Transplant (ANZDATA) Registry, South Australian Health \\ and Medical Research Institute (SAHMRI), Adelaide, Australia \\ ${ }^{4}$ Australasian Kidney Trials Network, University of Queensland, Brisbane, Australia \\ ${ }^{5}$ Adelaide Medical School, University of Adelaide, Adelaide, Australia \\ ${ }^{6}$ Translational Research Institute, Brisbane, Australia \\ ${ }^{7}$ School of Medicine, University of Queensland, Brisbane, Australia \\ ${ }^{8}$ Department of Nephrology, Monash Medical Centre, Melbourne, Australia \\ ${ }^{9}$ Department of Medicine, Monash University, Melbourne, Australia \\ ${ }^{10}$ School of Public Health and Preventive Medicine, Monash University, Melbourne, Australia \\ ${ }^{11}$ Eastern Health Clinical School, Monash University, Melbourne, Australia \\ ${ }^{12}$ School of Medicine, University of Melbourne, Melbourne, Australia \\ ${ }^{13}$ Department of Intensive Care, Austin Health, Melbourne, Australia \\ ${ }^{14}$ Department of Renal Medicine, Auckland District Health Board, Auckland, New Zealand \\ ${ }^{15}$ School of Medicine, University of Auckland, Auckland, New Zealand
}

This is the author manuscript accepted for publication and has undergone full peer review but has not been through the copyediting, typesetting, pagination and proofreading process, which may lead to differences between this version and the Version of Record. Please cite this article as doi: $10.1111 /$ nep.13782

This article is protected by copyright. All rights reserved. 
Running title: Dialysis duration over time $\&$ across centres

Abstract word count : 250 words

Manuscript word count : 3121 (main text)+ 250 (abstract)+ 624 (references) $=3995$ words

Address for Correspondence: Dr Isabelle Ethier, Department of Nephrology, Level 2, ARTS Building, Princess Alexandra Hospital, 199 Ipswich Road, Woolloongabba, Brisbane, QLD 4102, Australia. Email: isabelle.ethier@umontreal.ca

\section{ABSTRACT}

AIM: Haemodialysis treatment prescription varies widely internationally. This study explored patient- and centre-level characteristics associated with weekly haemodialysis hours.

METHODS: Australia and New Zealand Dialysis and Transplant (ANZDATA) Registry data was analysed. Characteristics associated with weekly duration were evaluated using mixed-effects linear regression models with patient- and centre-level covariates as fixed effects, and dialysis centre and state as random effects using the 2017 prevalent in-centre haemodialysis (ICHD) and home haemodialysis (HHD) cohorts. Evaluation of patterns of weekly duration over time analysed the 2000 to 2017 incident ICHD and HHD cohorts.

RESULTS: Overall, 12,494 ICHD and 1,493 HHD prevalent patients in 2017 were included. Median weekly treatment duration was 13.5 (interquartile range (IQR) 12-15) hours for ICHD and 16 (IQR 15-20) hours for HHD. Male sex, younger age, higher body mass index,

This article is protected by copyright. All rights reserved. 
arteriovenous fistula/graft use, Aboriginal and Torres Strait Islander ethnicity and longer dialysis vintage were associated with longer weekly duration for both ICHD and HHD. No centre characteristics were associated with duration. Variability in duration across centres was very limited in ICHD compared to HHD, with variation in HHD being associated with state. Duration did not vary significantly over time for ICHD, whereas longer weekly HHD treatments were reported between 2006 and 2012 compared to before and after this period.

CONCLUSION: This study in the Australian and New Zealand haemodialysis population showed that weekly duration was primarily associated with patient characteristics. No centre effect was demonstrated. Practice patterns seemed to differ across states/countries, with more variability in HHD than ICHD.

Key words: Dialysis, Dialysis duration, End-stage kidney disease, Haemodialysis, Treatment time

This article is protected by copyright. All rights reserved. 


\section{INTRODUCTION}

Optimal haemodialysis treatment duration has been the subject of much debate for many years. In 1981, the National Cooperative Dialysis Study, aiming to develop a definition of adequate long-term dialysis treatment by evaluating different concentrations of blood urea nitrogen (BUN) and treatment times, found that shorter treatment duration appeared to contribute to morbidity. ${ }^{1}$ Since then, many observational studies have associated longer dialysis duration with lower mortality. ${ }^{2-12}$ Among these, a registry analysis from Australia and New Zealand in 2006 concluded that the optimal combination of haemodialysis treatment for better survival appeared to be $\mathrm{Kt} / \mathrm{V} \geq 1.3$ and session length of $\geq 4.5$ hours. ${ }^{6}$ While most expert consensus guidelines around the world agree on the recommended haemodialysis dose measured by $\mathrm{Kt} / \mathrm{V}$, the minimum required treatment duration is still variable across countries. ${ }^{13,14}$ There are no current recommendations by the Caring for Australians with Renal Impairment (CARI) guidelines on duration and frequency of haemodialysis therapy as the last publication on the subject matter, in 2004, is now out of date. ${ }^{15}$ Thus, current clinical practice in terms of haemodialysis treatment duration is expected to be variable and it is unclear if available evidence has been translated into practice. There are also very few studies assessing the impact of centre characteristics on treatment duration..$^{2,10}$

This article is protected by copyright. All rights reserved. 
The aim of this study was to describe the patterns of haemodialysis treatment duration in Australia and New Zealand (ANZ) across centres and over time, and to identify the patient- and centre-level characteristics associated with weekly treatment duration in incentre haemodialysis (ICHD) and home haemodialysis (HHD) cohorts.

This article is protected by copyright. All rights reserved. 


\section{METHODS}

\section{Study Population}

All adult ( $\geq 18$ years) patients with at least one episode of chronic haemodialysis reported to the Australia and New Zealand Dialysis and Transplant (ANZDATA) Registry between 1 January 2000 and 31 December 2017 were eligible, including patients treated by peritoneal dialysis or kidney transplantation prior to haemodialysis commencement. Variation in weekly dialysis duration across centres and states was evaluated using a cohort of all prevalent haemodialysis patients in 2017 while temporal change in dialysis duration was evaluated using an incident cohort, which included all patients who initiated haemodialysis in Australia and New Zealand during the study period. ICHD and HHD cohorts were analysed separately.

De-identified data from ANZDATA were used with permission granted by the ANZDATA registry executive. This study was approved by the Metro South Human Research Ethics Committee (LNR/2019/QMS/53440).

\section{Study Outcomes}

The primary outcome was weekly treatment duration in hours, calculated as the number

of treatment sessions per week multiplied by the session duration. For the 2017

This article is protected by copyright. All rights reserved. 
prevalent cohort, data on weekly treatment duration and potential patient- and centrelevel predictor variables were extracted from the annual survey reported on 31 December.

Patient-level characteristics included dialysis vintage, first kidney replacement therapy modality, sex, age, body mass index (BMI), ethnicity, causes of end-stage kidney disease, comorbidities, smoking status, blood flow rate and vascular access. Centre-level characteristics analysed in this study were transplantation centre, remoteness area (major city, regional, remote), centre size (number of prevalent dialysis patients in the centre) and proportion of prevalent dialysis patients on home therapies (peritoneal dialysis and HHD). For the purpose of analyses, the country of New Zealand and every Australian state and territory were considered as a 'state' of residence.

The incident cohort included all patients initiating dialysis during the study period. In this cohort, weekly duration was calculated using data from the first report to the ANZDATA registry following dialysis initiation. Between 2000 and 2003, weekly duration was reported biannually on 31 March and 31 September; in 2004, it was reported on 31 March and 31 December; and from 2005 to 2017, it was annually reported on 31 December.

\section{Statistical Analyses}

This article is protected by copyright. All rights reserved. 
Patient and centre characteristics were expressed as frequency (percentage) for categorical variables and median (interquartile range) for non-normally distributed continuous variables. Predictors of weekly duration were analysed by multilevel mixedeffects linear regression models with patient- and centre-level covariates as fixed effects. Dialysis centre and state were included as random effects, such that patients were nested within centres and centres were nested within states. Patient- and centre-level characteristics were included in the multivariable analysis if they had P-values $<0.2$ in univariable analyses. Analyses were performed using Stata (version 15.1; StataCorp LLC, Texas, USA). Two-sided $\mathrm{P}<0.05$ was considered statistically significant.

This article is protected by copyright. All rights reserved. 


\section{RESULTS}

Duration of haemodialysis for the 2017 prevalent cohort

Among 13,987 patients who received haemodialysis in 2017 , there were 12,494 ICHD and 1,493 HHD patients (Table 1). Median weekly treatment duration was 13.5 (interquartile range [IQR] 12-15) hours (range 2 to 32 hours) for ICHD and 16 (IQR 15-20) hours (range 4 to 70 hours) for HHD (Table 2). Weekly duration $<12$ hours was infrequent ( $7 \%$ on ICHD and $2 \%$ on HHD). Treatment duration of $\geq 20$ hours per week represented only $1 \%$ of ICHD patients but accounted for $31 \%$ of HHD patients. There was more variability in dialysis schedules in HHD than ICHD (Table 2): Ninety-six percent of patients were treated thrice weekly with ICHD, whereas $48 \%$ of HHD patients were treated 3 times per week, $26 \%$ on alternate days (3.5 times per week) and $24 \%$ underwent 4 or more sessions weekly. Session duration ranged from 4 to 5 hours for $93 \%$ of ICHD patients vs. $66 \%$ of HHD patients, with an additional $30 \%$ of patients treated for more than 5 hours per session in the latter cohort.

Included ICHD patients were treated in 89 different centres in 2017, whereas HHD patients' care was managed by 59 centres (Table 3). Median weekly duration per centre was 13.5 (IQR 12-13.5) hours for ICHD and 16 (IQR 15-18) hours for HHD (Figure 1A).

This article is protected by copyright. All rights reserved. 


\section{Predictors of weekly haemodialysis duration for the 2017 prevalent cohort}

In the multivariable mixed-effects linear regression model, male sex, younger age, higher body mass index (BMI), arteriovenous fistula/arteriovenous graft (AVF/AVG) use (compared to central venous catheter), dialysis vintage, Aboriginal and Torres Strait Islander, Pacific Islander and Māori ethnicities (compared to Caucasian), peritoneal dialysis as the first kidney replacement therapy (compared to ICHD), and higher blood flow rate were associated with longer weekly duration of ICHD (Table 4). Using the same regression model, male sex, younger age, higher BMI, AVF/AVG as the vascular access, dialysis vintage, and Aboriginal and Torres Strait Islander ethnicity were also associated with a longer weekly duration of HHD (Table 4). However, a lower blood flow rate was associated with longer treatment hours on HHD, which includes nocturnal treatment. No patient comorbidity or centre-level characteristic was significantly associated with weekly HD duration for either ICHD or HHD patients in the multilevel mixed-effects model.

Variability in median weekly duration across centres was very limited in ICHD compared to HHD (Figure 1B). However, the number of patients per centre on HHD were appreciably smaller (84 [IQR 26-210] patients per centre on ICHD vs. 16 [IQR 7-31] patients per centre on HHD). Variability in weekly duration was more influenced by the Australian states/New Zealand than by the centres and some of the centre characteristics evaluated in this study

This article is protected by copyright. All rights reserved. 
were highly correlated with the states. This variability across states was more pronounced in HHD than in ICHD (Figure 2).

\section{Temporal change in dialysis duration in incident haemodialysis patients over time}

The number of incident ICHD and HHD patients increased between 2000 and 2017 (Supplementary Table 1). Age, BMI and burden of baseline comorbidities of incident patients also increased from 2000 to 2017 (Supplementary Figure 1). Median weekly dialysis duration remained relatively stable over time in ICHD at 12 (12-13.5) hours per week. In contrast, more temporal variation in median weekly duration was recorded in HHD, reaching a maximum of 18 (15-24) hours per week in 2007 , at which time less than $20 \%$ of HHD patients were treated for less than 15 hours weekly (Figure 3). Weekly HHD duration progressively decreased in the following years and has remained overall stable since 2012 , with approximately $30 \%$ of patients treated for $<15$ hours per week and around $25 \%$ of patients undergoing $\geq 20$ hours of haemodialysis weekly. From 2012 onwards, shorter weekly treatment duration ( $<12$ hours per week) has also re-emerged, representing around 5\% of HHD patients' weekly durations.

This article is protected by copyright. All rights reserved. 


\section{DISCUSSION}

This binational registry study showed that HHD is associated with longer weekly treatment time compared with ICHD. There was minimal variation in weekly treatment duration of ICHD across centres and over time in Australia and New Zealand (ANZ) and no centre characteristics were identified as predictors of treatment time. HHD weekly treatment duration was more variable across patients, centres and over time during the period of 2000 to 2017 compared to ICHD. Weekly haemodialysis duration appeared to vary more across states/countries, than between centres and variability was particularly pronounced in HHD.

Longer weekly duration was recorded in HHD than in ICHD, with a wider range of treatment times. A European study assessing treatment duration from the ERA-EDTA Registry also found that patients on extended-hours haemodialysis (defined as thrice weekly $\geq 6$-hours sessions) were more often treated at home than patients on conventional haemodialysis (thrice weekly 3.5 to 4 -h sessions) (6\% vs. $0 \%$ ). ${ }^{12}$ In ANZ, no financial incentives or penalties and no official policies or guidelines are in place regarding the required treatment duration. The last published Caring for Australians with Renal Impairment (CARI) Guidelines on duration and frequency of haemodialysis therapy date back to 2004 and indicated that no recommendation was possible based on Level I or II

This article is protected by copyright. All rights reserved. 
evidence. ${ }^{15}$ The current study shows that general practice across ANZ in 2017 appeared to be based on thrice weekly sessions of $4,4.5$ or 5 hours.

This registry study showed that less than $10 \%$ of prevalent ICHD patients were treated for $<12 \mathrm{~h}$ per week in ANZ in 2017. Only 5\% of patients had treatment times shorter than 4 hours per session, which contrasts vividly with current practices in the USA. In a recent study by Swaminathan et al., 86,893 American patients were initiated on ICHD, of whom $55 \%$ were treated in 631 facilities ( $43 \%$ of all centres) with a uniform treatment time of 3 hours per session three times per week. ${ }^{10}$ In Europe, Fotheringham et al. reported about half (52\%) of patients on thrice weekly ICHD being treated for approximately 4 hours (226250 minutes) per session in a cohort of 19,557 prevalent patients participating in the DOPPS from 1998 to 2011, while about 29\% of patients were undergoing sessions of less than 4 hours. ${ }^{11}$

One of the main advantages attributed to HHD compared to ICHD regarding patient relevant outcomes, such as quality of life and life participation, is the flexibility of treatment schedules, including nocturnal sessions. Few studies have been published describing weekly duration and schedule pattern in HHD around the world. While HHD has often been associated with short frequent or long hours haemodialysis, about half of

This article is protected by copyright. All rights reserved. 
HHD patients (48\%) in the present study were on a thrice weekly schedule and an additional $26 \%$ of patients were treated on alternate days. The remaining quarter of patients were on more intensive schedules ( 4 or more sessions per week). The higher weekly treatment duration recorded in HHD compared to ICHD in ANZ appears to be mostly due to longer sessions, with about $30 \%$ of patients being treated for more than 5 hours per session. Consequently, up to $79 \%$ of HHD patients in ANZ undergo $\geq 15$ hours per week, which would be considered as 'intensive' haemodialysis in many countries. Choices in both frequency and duration of sessions could have been influenced by various patient factors (such as employment, personal preference, presence of a caregiver or even pregnancy) and practice patterns across centres or states (for example, more experience with nocturnal dialysis).

In keeping with previous studies, younger age,,$^{2,5,6,8,9}$ male sex, ${ }^{2,5,6,8,9}$ higher $\mathrm{BMI}^{5,6,8,9}$ and higher dialysis vintage ${ }^{5,8}$ were associated with longer weekly duration. As also described by Marshall et al. in 2006, ${ }^{6}$ patients of Aboriginal, Māori, Torres Strait and Pacific Island descent were more likely to be treated with longer weekly duration on ICHD, although no association was found for Māori and Pacific Islanders on HHD. Higher blood flow rate was more likely with longer hours on ICHD, whereas lower blood flood rate was associated with longer hours on HHD, which is expected in patients undergoing long hours/nocturnal 
HHD. Contrary to previous studies, ${ }^{5,6,9,11}$ none of the evaluated comorbidities (diabetes mellitus, coronary artery disease, cerebrovascular disease, peripheral vascular disease and chronic lung disease) were found to be associated with treatment duration. It should be noted that various regression models were explored, but none showed a good model fit (low R-squared values), partly because of the limited nature of the data collected by the registry. None of the models could efficiently capture the complexity of the factors involved. Therefore, we have decided on a descriptive approach of the variables associated with longer weekly duration rather than emphasizing the specific magnitudes of the coefficients. The final model chosen, while additionally taking into account the structure in the data (patients nested within centres; centres nested within states), agreed with the other models explored and the descriptive analyses.

Variability in median weekly duration across centres was very limited in ICHD. While showing higher variation in HHD, the median number of patients on HHD per centre was very low, resulting in extreme values from small centres. In multivariable mixed-effects linear regression model, none of the centre characteristics assessed was associated with weekly dialysis duration. However, there was a strong association between Australian states/New Zealand and treatment duration. It should also be noted that some of the evaluated characteristics were correlated with the states (for example, there was no 
transplanting centre in the Northern Territory, Tasmania or the Australian Capital Territory). The variability in weekly duration practices across states appeared more pronounced for HHD than for ICHD. Contrary to the present findings, previous American studies have identified centre-level characteristics associated with different practice patterns in terms of treatment duration. ${ }^{2,10}$ In 2017, in a study comparing patients initiating haemodialysis in facilities with schedules of 3 hours per session vs. $\geq 4$ hours per session, 3-hour facilities were more likely to have evening dialysis sessions, were less likely to reuse dialyzers and to accept transient patients, and had a higher total number of patients located within their zip code. ${ }^{10}$ The identification of centre characteristics associated with dialysis duration in those publications, compared to the present study, could be explained by the variability in payment/reimbursement policies in regards to dialysis between countries and related to other differences in clinical practices (e.g. the reuse of dialyzers in the USA).

Of note, in New Zealand, a smaller difference is noted between ICHD and HHD weekly hours compared to Australian states: up to $35 \%$ of ICHD patients were treated with $\geq 15$ hours, whereas about $25 \%$ of HHD patients were part of the highest category of duration ( $\geq 20$ hours/week), a lower proportion than in most Australian states. This apparent

This article is protected by copyright. All rights reserved. 
restriction in more extended HHD hours in New Zealand might be explained by the utilisation of independent community house haemodialysis. ${ }^{16}$ In this submodality of HHD, patients undertake independent haemodialysis in nonmedical community-based homelike settings, without direct nursing or medical supervision. Although these facilities offer more flexibility and autonomy than ICHD, resource limitations can still restrict the weekly treatment duration.

Previously conducted analysis of the ANZDATA registry, published in 2006, showed an association between $\mathrm{Kt} / \mathrm{V}$ of 1.30-1.39 and session length of 4.5-4.9 hours with the lowest mortality risk, which supports inclusion of treatment time within the definition of adequate haemodialysis practice ${ }^{6}$ Although no updated guidelines were published in ANZ following this publication, the present study showed a trend towards longer dialysis duration in the following years. This increase was quite modest in ICHD practices where it seemed to peak around 2012 with $26 \%$ of ICHD patients being treated for $\geq 15$ hours per week, after which this proportion progressively declined to $22 \%$ in 2017 . The increase in the absolute number of prevalent ICHD patients might explain this decrease, due to limited resources and possible saturation of centres. In HHD, where facility resource limitation is not a factor in terms of time restriction, a clearer demarcation in weekly duration increase was observed in the period surrounding the publication of the 
aforementioned ANZ study. However, this trend towards longer weekly treatment hours was not sustained and the distribution of duration reported in the most recent years resembled that of 2004-2005. Over the years, changes in the perspectives of patient important outcomes (such as quality of life, flexibility of schedule, ability to work and travel, or lifestyle considerations, as also reported by recent patient-centered research ${ }^{17}$ ) as relevant factors involved in dialysis duration decision, rather than mortality alone, might have influenced the trends. Furthermore, in the last decade, randomized trials were published comparing more frequent or extended hours dialysis to conventional haemodialysis, mainly the Canadian study by Culleton et $\mathrm{al}^{18}$ the Frequent Hemodialysis Network (FHN) Daily ${ }^{19}$ and Nocturnal ${ }^{20}$ studies, and the ACTIVE trial. ${ }^{21}$ Although beneficial effects on left ventricular mass, serum phosphate, systolic blood pressure and quality of life have been demonstrated, ${ }^{18-21}$ long term follow-up data have been conflicting with no consistent mortality benefit ${ }^{27,28}$ and harms reported, including vascular access complications, ${ }^{19,20}$ perceived caregiver burden ${ }^{22}$ and loss of residual kidney function. ${ }^{23}$ Considerations of these reports might have been one of the driving forces in limiting the efforts towards more frequent or longer hour treatments. The progressive ageing and higher comorbidity burden of the dialysis population and the move towards 'palliative' dialysis over the years could also be factors influencing weekly treatment duration.

This article is protected by copyright. All rights reserved. 
The strengths of this registry study include its large sample size (including both ICHD and HHD patients), and the inclusion of both an incident and a prevalent cohort enabling assessment of weekly duration across centres and over time throughout a long evaluation period. However, these strengths have to be balanced against important limitations. Pertaining to the nature of registry analysis, this study is limited by the depth of data available and possible coding bias or error in reporting. Important patient characteristics of relevance in terms of weekly treatment duration were missing. Those included, but were not limited to, residual kidney function, quality of life, employment/life participation and presence of a support person at home. Moreover, other relevant centre characteristics are not available from registry data, such as saturation of centres, nurseand doctor-to-patient ratios and private/public status of the centres. Thus, residual confounding could not be excluded, and the complexity of the factors involved could not be captured aptly by the models explored. Finally, this study describes practice patterns in ANZ, where home therapies are widely used in a government funded health system including dialysis treatment, which may not be generalisable to other countries, particularly if different dialysis reimbursement policies are in place.

This article is protected by copyright. All rights reserved. 
In conclusion, this registry study of the ANZ haemodialysis population showed that patient-level characteristics are the main determinants of weekly dialysis duration, while no centre effect was demonstrated. Moreover, practice patterns varied markedly across states/countries. The relative absence of resource restrictions in HHD appears to be of prime importance in permitting flexibility in dialysis schedules and longer weekly treatment duration, while also allowing practice patterns to change more freely and permit greater emphasis on patient relevant outcomes and preferences. This reinforces the need for greater support of home dialysis uptake and maintenance across the world, particularly in an era of infrastructural resources' limitation and growing global dialysis populations.

This article is protected by copyright. All rights reserved. 


\section{ACKNOWLEDGMENTS}

The authors gratefully acknowledge the contributions of the entire Australia and New Zealand nephrology community (physicians, surgeons, database managers, nurses, renal operators, and patients) in providing information for and maintaining the ANZDATA database. Reporting and interpretation of these data should in no way be seen as an official policy or interpretation of the ANZDATA Registry and are the responsibility of the authors. IE would like to acknowledge the Centre Hospitalier de l'Université de Montréal and the Fondation du CHUM for their support through a fellowship grant. ES receives support from the National Health and Medical Research Council (Postgraduate Scholarship) and the Royal Australasian College of Physicians (NHMCR Jacquot Award for Excellence). AV receives grant support from the Royal Australasian College of Physicians (Jacquot Research Establishment Award) and the Princess Alexandra Research Foundation. DJ is supported by an Australian National Health and Medical Research Council (NHMRC) Practitioner Fellowship. YC is supported by an Australian NHMRC Early Career Fellowship.

\section{CONFLICT OF INTEREST/DISCLOSURES}

YC reports personal fees from Baxter, and grant support from Fresenius Medical Care, PKD Australia, NHMRC and Baxter CEC Grant, outside the submitted work. CD reports 
grant support from NHMRC, outside the submitted work. $\mathrm{CH}$ reports personal fees from Janssen, GlaxoSmithKline and Osuka, and grant support from Baxter, Fresenius, Shire, PKD Aus and NHMRC, outside the submitted work. KRP declared having received consultancy fees from Medtronic Australasia Pty Ltd and grant support from NHMRC outside the submitted work. DJ reports personal fees from AWAK, Astra-Zeneca, Baxter Healthcare and Fresenius Medical Care, and grant support from Baxter Extramural Grant and Baxter CEC Grant, outside the submitted work. The other authors do not have any interest in the information contained in the manuscript to disclose.

This article is protected by copyright. All rights reserved. 


\section{REFERENCES}

1. Lowrie EG, Laird NM, Parker TF, Sargent JA. Effect of the hemodialysis prescription on patient morbidity: Report from the National Cooperative Dialysis Study. N Engl J Med. 1981;305:1176-1181.

2. Held PJ, Levin NW, Bovbjerg RR, Pauly M V., Diamond LH. Mortality and Duration of Hemodialysis Treatment. JAMA J Am Med Assoc. 1991;265:871-875.

3. Valderrabano F. Weekly duration of dialysis treatment - does it matter for survival? Nephrol Dial Transplant. 1996;11:569-572.

4. Shinzato T, Nakai S, Akiba T, et al. Survival in long-term haemodialysis patients: Results from the annual survey of the Japanese Society for Dialysis Therapy. Nephrol Dial Transplant. 1997;12:884-888.

5. Saran R, Bragg-Gresham JL, Levin NW, et al. Longer treatment time and slower ultrafiltration in hemodialysis: Associations with reduced mortality in the DOPPS. Kidney Int. 2006;69:1222-1228.

6. Marshall MR, Byrne BG, Kerr PG, McDonald SP. Associations of hemodialysis dose and session length with mortality risk in Australian and New Zealand patients. Kidney Int. 2006;69:1229-1236.

7. Brunelli SM, Chertow GM, Ankers ED, Lowrie EG, Thadhani R. Shorter dialysis times are associated with higher mortality among incident hemodialysis patients.

This article is protected by copyright. All rights reserved. 
Kidney Int. 2010;77:630-636.

8. Tentori F, Zhang J, Li Y, et al. Longer dialysis session length is associated with better intermediate outcomes and survival among patients on in-center three times per week hemodialysis: Results from the Dialysis Outcomes and Practice Patterns Study (DOPPS). Nephrol Dial Transplant. 2012;27:4180-4188.

9. Flythe JE, Curhan GC, Brunelli SM. Shorter length dialysis sessions are associated with increased mortality, independent of body weight. Kidney Int. 2012;83:104113.

10. Swaminathan S, Mor V, Mehrotra R, Trivedi AN. Initial Session Duration and Mortality Among Incident Hemodialysis Patients. Am J Kidney Dis. 2017;70:69-75.

11. Fotheringham J, Sajjad A, Stel VS, et al. The association between longer haemodialysis treatment times and hospitalization and mortality after the twoday break in individuals receiving three times a week haemodialysis. Nephrol Dial Transplant. 2019;34:1577-1584.

12. Jansz TT, Noordzij M, Kramer A, Laruelle E. Survival of patients treated with extended-hours haemodialysis in Europe : an analysis of the ERA-EDTA Registry. Nephrol Dial Transplant. 2019:1-8.

13. Tattersall J, Martin-Malo A, Pedrini L, et al. EBPG guideline on dialysis strategies. Nephrol Dial Transplant. 2007;22(SUPPL.2).

This article is protected by copyright. All rights reserved. 
14. National Kidney Foundation. KDOQI Clinical Practice Guideline for Hemodialysis Adequacy: 2015 Update. Am J Kidney Dis. 2015;66:884-930.

15. Caring for Australians with Renal Impairment. The CARI Guidelines: Duration and frequency of haemodialysis therapy.

http://www.cari.org.au/archived_guidelines.html. Published 2005. Accessed December 3, 2019.

16. Marshall MR, van der Schrieck N, Lilley D, et al. Independent Community House Hemodialysis as a Novel Dialysis Setting: An Observational Cohort Study. Am J Kidney Dis. 2013;61:598-607.

17. Urquhart-Secord R, Craig JC, Hemmelgarn B, et al. Patient and Caregiver Priorities for Outcomes in Hemodialysis: An International Nominal Group Technique Study. Am J Kidney Dis. 2016;68:444-454.

18. Culleton B, Walsh M, Quinn R, Donnelly S, Friedrich M, Kumar a. Effect of frequent nocturnal hemodialysis vs conventional hemodialysis. J Am Med Assoc. 2007;298:1291-1299.

19. Chertow GM, Levin NW, Beck GJ, et al. In-Center Hemodialysis Six Times per Week versus Three Times per Week. N Engl J Med. 2010;363:2287-2300.

20. Rocco M V., Lockridge RS, Beck GJ, et al. The effects of frequent nocturnal home hemodialysis: The Frequent Hemodialysis Network Nocturnal Trial. Kidney Int.

This article is protected by copyright. All rights reserved. 
2011;80:1080-1091.

21. Jardine MJ, Zuo L, Gray NA, et al. A trial of extending hemodialysis hours and quality of life. J Am Soc Nephrol. 2017;28:1898-1911.

22. Suri RS, Larive B, Garg AX, et al. Burden on caregivers as perceived by hemodialysis patients in the Frequent Hemodialysis Network (FHN) trials. Nephrol Dial Transplant. 2011;26:2316-2322.

23. Daugirdas JT, Greene T, Rocco M V., et al. Effect of frequent hemodialysis on residual kidney function. Kidney Int. 2013;83:949-958.

\title{
SUPPORTING INFORMATION
}

Supplemental Table 1. Weekly dialysis duration of incident haemodialysis patients over time.

\begin{abstract}
Supplementary Figure 1. Trends over time for baseline characteristics of incident patients on in-centre [A] and home haemodialysis [B]. Note: Continuous variables are expressed as median values for each year (age in years and $\mathrm{BMI}$ in $\mathrm{kg} / \mathrm{m}^{2}$ ); categorical variables for comorbidities are represented as percentage (\%) of incident patients for each year. $B M I=$ body mass index; $C A D=$ coronary artery disease; cerebrovascular = cerebrovascular disease; $P V D=$ peripheral vascular disease; chronic lung = chronic lung disease.
\end{abstract}

This article is protected by copyright. All rights reserved. 
Figure 1. Distribution of median weekly duration [A] and variability of weekly duration [B] across centres on in-centre and home haemodialysis. Note: Two outlier values (weekly duration of 56 and 70 hours) are not shown on the home haemodialysis figure $B$ for better visualisation of the overall values.

Figure 2. Distribution of weekly treatment duration across states ${ }^{\dagger}$ on in-centre $[\mathrm{A}]$ and home haemodialysis [B].

${ }^{\dagger}$ For the purpose of analyses, New Zealand and Australian territories were considered as a 'state'. ACT = Australian Capital Territory; NSW = New South Wales; NT = Northern Territory; NZ = New Zealand; $\mathrm{QLD}=$ Queensland; $\mathrm{SA}=$ South Australia; $\mathrm{TAS}=$ Tasmania; VIC = Victoria; WA = Western Australia.

Figure 3. Distribution of weekly treatment duration over time on in-centre $[A]$ and home haemodialysis [B]. 
Table 1. Characteristics of prevalent haemodialysis patients in 2017.

\begin{tabular}{|l|c|c|}
\hline & IN-CENTRE HD & HOME HD \\
\hline N= & 12494 & 1493 \\
\hline Dialysis vintage (in years) & $3.4(1.4-6.5)$ & $4.8(2.5-8.4)$ \\
\hline First kidney replacement & & \\
therapy modality & & \\
In-centre HD & $10503(84 \%)$ & $1092(73 \%)$ \\
Home HD & $61(0.5 \%)$ & $141(9 \%)$ \\
Peritoneal dialysis & $1871(15 \%)$ & $231(15 \%)$ \\
Graft & $59(0.5 \%)$ & $29(2 \%)$ \\
\hline Sex & & \\
Female & $5131(41 \%)$ & $460(31 \%)$ \\
Male & $7363(59 \%)$ & $1033(69 \%)$ \\
\hline Age at first HD (in years) & $63(51-72)$ & $51(41-60)$ \\
\hline Age in 2017 (in years) & $67(55-76)$ & $56(47-65)$ \\
\hline Late referral to & $2418(20 \%)$ & $219(15 \%)$ \\
nephrologist care ${ }^{\dagger}$ & & \\
\hline Ethnicity & & \\
Caucasian & & \\
Indigenous Australian ${ }^{\ddagger}$ & $1684(13 \%)$ & $99(7 \%)$ \\
Asian & $1094(9 \%)$ & $131(9 \%)$ \\
Māori & $740(6 \%)$ & $165(11 \%)$ \\
Pacific Islander & $892(7 \%)$ & $184(12 \%)$ \\
Other & $446(4 \%)$ & $50(3 \%)$ \\
Not reported & $235(2 \%)$ & $18(1 \%)$ \\
\hline Primary kidney disease & & \\
Diabetic nephropathy & $5345(43 \%)$ & $462(31 \%)$ \\
Glomerulonephritis & $2335(19 \%)$ & $468(31 \%)$ \\
Hypertension & $1627(13 \%)$ & $130(9 \%)$ \\
Polycystic disease & $598(5 \%)$ & $136(9 \%)$ \\
Other & $1762(14 \%)$ & $236(16 \%)$ \\
Uncertain/Not reported & $827(7 \%)$ & $61(4 \%)$ \\
\hline Body mass index (kg/m²) & $28.7(24.6-34.0)$ & $31.2(25.7-38.0)$ \\
\hline Smoking status & & \\
Never & & $574(477 \%)$ \\
Former & & $209(14 \%)$ \\
\hline Current & & \\
\hline
\end{tabular}

This article is protected by copyright. All rights reserved. 


\begin{tabular}{|l|c|c|}
\hline State or country & & \\
New South Wales & $3036(24 \%)$ & $433(29 \%)$ \\
Victoria & $2612(21 \%)$ & $181(12 \%)$ \\
Queensland & $2076(17 \%)$ & $238(16 \%)$ \\
Northern Territory & $640(5 \%)$ & $38(3 \%)$ \\
South Australia & $774(6 \%)$ & $33(2 \%)$ \\
Western Australia & $1139(9 \%)$ & $98(7 \%)$ \\
Tasmania & $203(2 \%)$ & $10(1 \%)$ \\
Australian Capital Territory & $161(1 \%)$ & $20(1 \%)$ \\
New Zealand & $1752(14 \%)$ & $442(30 \%)$ \\
\hline Comorbidities ${ }^{\dagger \dagger}$ & & \\
Diabetes mellitus & $7127(57 \%)$ & $658(44 \%)$ \\
Coronary artery disease & $5236(42 \%)$ & $432(29 \%)$ \\
Cerebrovascular disease & $1941(16 \%)$ & $123(8 \%)$ \\
Peripheral vascular disease & $2978(24 \%)$ & $215(14 \%)$ \\
Chronic lung disease & $2196(18 \%)$ & $213(14 \%)$ \\
\hline Blood flow rate (mL/min) ${ }^{\ddagger \ddagger}$ & $300(300-300)$ & $300(265-300)$ \\
\hline Current vascular access $\$ \S$ & & \\
AVF / AVG & $9720(78 \%)$ & $1389(81 \%)$ \\
Central venous catheter & $2746(22 \%)$ & $102(19 \%)$ \\
\hline
\end{tabular}

Values are expressed as frequency (percentage) for categorical variables and median (interquartile range) for non-normally distributed continuous variables.

AVF/AVG = arteriovenous fistula/arteriovenous graft; $H D=$ haemodialysis.

${ }^{\dagger}$ Data on late referral to nephrologist care (<3 months before commencement of kidney replacement therapy) were missing for $2 \%$ of patients.

${ }^{\ddagger}$ Indigenous Australian refers to Aboriginal and Torres Strait Islander

$\S$ Data on body mass index were missing for $2 \%$ of patients.

"Data on smoking status were missing for $2 \%$ of patients.

${ }^{\dagger \dagger}$ Data on comorbidities were missing for less than $0.3 \%$ of patients.

㧊 Data on blood flow rate were missing for less than $0.1 \%$ of patients.

$\S \S$ Data on vascular access were missing for $0.2 \%$ of patients. 
Table 2. Dialysis duration and schedule of prevalent haemodialysis patients in 2017.

\begin{tabular}{|l|c|c|}
\hline & $\begin{array}{c}\text { IN-CENTRE HD } \\
\mathbf{N}=\mathbf{1 2 4 9 4}\end{array}$ & $\begin{array}{c}\text { HOME HD } \\
\mathbf{N}=\mathbf{1 4 9 3}\end{array}$ \\
\hline $\begin{array}{l}\text { Weekly duration (in hours) } \\
\text { Median (interquartile range) }\end{array}$ & $13.1 \pm 2.0$ & $18.2 \pm 6.2$ \\
\hline Weekly duration by categories & $13.5(12-15)$ & $16(15-20)$ \\
$<12$ hours & $872(7 \%)$ & $34(2 \%)$ \\
$12-<15$ hours & $8053(64 \%)$ & $285(19 \%)$ \\
$15-<20$ hours & $3468(28 \%)$ & $712(48 \%)$ \\
$20+$ hours & $101(1 \%)$ & $462(31 \%)$ \\
\hline Number of sessions per week & $368(3 \%)$ & $17(1 \%)$ \\
$<3$ sessions & $11972(96 \%)$ & $722(48 \%)$ \\
3 sessions & $19(<1 \%)$ & $391(26 \%)$ \\
3.5 sessions (alternate days) & $129(1 \%)$ & $363(24 \%)$ \\
$4+$ sessions & $606(5 \%)$ & $47(3 \%)$ \\
\hline Number of hours per session & $5291(42 \%)$ & $273(18 \%)$ \\
$<4$ hours & $3055(25 \%)$ & $183(12 \%)$ \\
4 hours & $3181(26 \%)$ & $542(36 \%)$ \\
$>4-<5$ hours & $313(3 \%)$ & $265(18 \%)$ \\
5 hours & $48(<1 \%)$ & $183(12 \%)$ \\
$>5-<8$ hours & & \\
$8+$ hours & & \\
\hline
\end{tabular}

Values are expressed as frequency (percentage) for categorical variables.

$\mathrm{HD}=$ haemodialysis

This article is protected by copyright. All rights reserved. 
Table 3. Centre characteristics for prevalent haemodialysis patients in 2017.

\begin{tabular}{|l|c|c|}
\hline & IN-CENTRE HD & HOME HD \\
\hline \multicolumn{1}{|c|}{ N centres } & 89 & $\mathbf{5 9}^{\dagger}$ \\
\hline Number of included patients per centre & $84(26-210)$ & $16(7-31)$ \\
\hline Transplant centre & $20(22 \%)$ & $20(34 \%)$ \\
\hline Remoteness area & $60(67 \%)$ & $37(63 \%)$ \\
Major city & $28(31 \%)$ & $21(36 \%)$ \\
Regional & $1(1 \%)$ & $1(2 \%)$ \\
Remote & $95(49-284)$ & $194(95-337)$ \\
\hline Centre size (number of prevalent & & \\
dialysis patients) & $23(0-31)$ & $28(23-35)$ \\
\hline Proportion of prevalent dialysis patients & & \\
on home therapies (in \%) & & $18(31 \%)$ \\
\hline State or country & $25(28 \%)$ & $9(15 \%)$ \\
New South Wales & $18(20 \%)$ & $11(19 \%)$ \\
Victoria & $24(27 \%)$ & $2(3 \%)$ \\
Queensland & $2(2 \%)$ & $2(3 \%)$ \\
Northern Territory & $2(2 \%)$ & $3(5 \%)$ \\
South Australia & $3(3 \%)$ & $2(3 \%)$ \\
Western Australia & $2(2 \%)$ & $1(2 \%)$ \\
Tasmania & $2(2 \%)$ & $11(19 \%)$ \\
Australian Capital Territory & $11(12 \%)$ & \\
New Zealand & & \\
\hline
\end{tabular}

Values are expressed as frequency (percentage) for categorical variables and median (interquartile range) for continuous variables.

†The 59 centres from which home HD patients' care was managed are a subset of the 89 in-centre HD centres.

$\mathrm{HD}=$ haemodialysis

This article is protected by copyright. All rights reserved. 
Table 4. Mixed-effects linear regression analyses of weekly duration (in hours) of incentre and home haemodialysis in the $\mathbf{2 0 1 7}$ prevalent cohort.

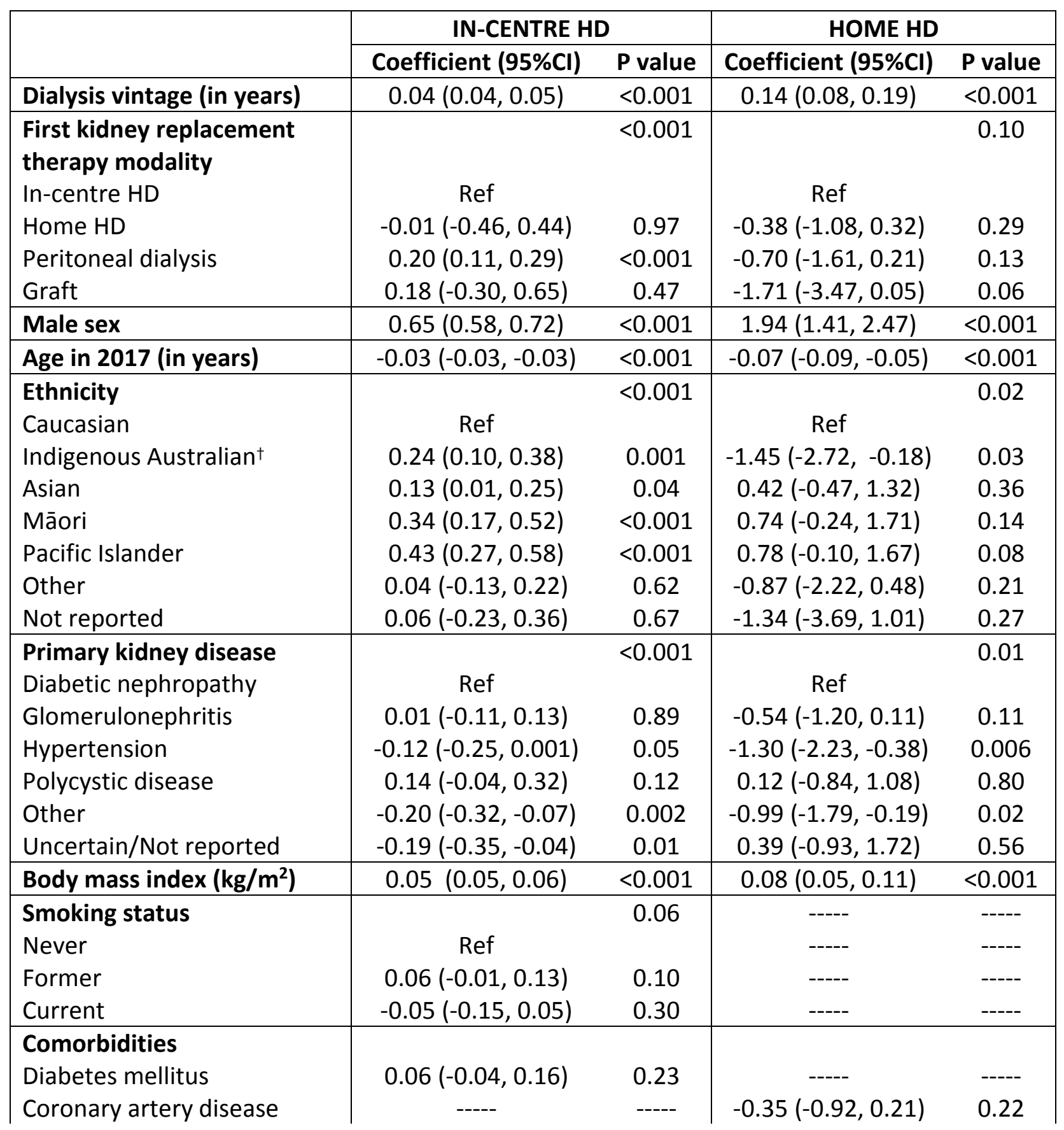

This article is protected by copyright. All rights reserved. 


\begin{tabular}{|c|c|c|c|c|}
\hline $\begin{array}{l}\text { Cerebrovascular disease } \\
\text { Peripheral vascular disease }\end{array}$ & $\begin{array}{c}-0.05(-0.14,0.04) \\
0.04(-0.04,0.12)\end{array}$ & $\begin{array}{l}0.31 \\
0.32\end{array}$ & $\begin{array}{c}-0.36(-1.24,0.52) \\
---\end{array}$ & 0.42 \\
\hline Blood flow rate (mL/min) & $0.005(0.004,0.006)$ & $<0.001$ & $-0.04(-0.04,-0.03)$ & $<0.001$ \\
\hline $\begin{array}{l}\text { Current vascular access } \\
\text { AVF / AVG } \\
\text { Central venous catheter }\end{array}$ & $\begin{array}{c}\text { Ref } \\
-0.40(-0.48,-0.31)\end{array}$ & $<0.001$ & $\begin{array}{c}\operatorname{Ref} \\
-2.09(-3.06,-1.12)\end{array}$ & $<0.001$ \\
\hline Transplant centre & ----- & ----- & $0.04(-2.12,2.20)$ & 0.97 \\
\hline $\begin{array}{l}\text { Remoteness area } \\
\text { Major city } \\
\text { Regional } \\
\text { Remote }\end{array}$ & $\begin{array}{c}\text { Ref } \\
-0.21(-0.59,0.18) \\
-0.21(-1.73,1.31) \\
\end{array}$ & $\begin{array}{l}0.29 \\
0.78 \\
\end{array}$ & $\begin{array}{c}\text { Ref } \\
-0.12(-2.51,2.27) \\
-0.23(-7.44,6.99) \\
\end{array}$ & $\begin{array}{l}0.92 \\
0.95 \\
\end{array}$ \\
\hline $\begin{array}{l}\text { Centre size (number of } \\
\text { prevalent dialysis patients) } \\
< \\
<50 /<96 \text { patients } \\
50-284 \text { / } 96-337 \text { patients } \\
>284 />337 \text { patients }\end{array}$ & $\begin{array}{c}0.25(-0.46,0.96) \\
\text { Ref } \\
-0.09(-0.49,0.31)\end{array}$ & $\begin{array}{l}0.49 \\
0.67\end{array}$ & $\begin{array}{c}-0.38(-2.87,2.10) \\
\operatorname{Ref} \\
-0.14(-2.44,2.15)\end{array}$ & 0.76 \\
\hline $\begin{array}{l}\text { Proportion of prevalent } \\
\text { dialysis patients on home } \\
\text { therapies (in \%) } \\
0 /<24 \% \\
1-31 / 24-35 \% \\
>31 />35 \%\end{array}$ & $\begin{array}{c}-0.38(-1.07,0.32) \\
\operatorname{Ref} \\
-0.03(-0.43,0.37)\end{array}$ & 0.29 & $\begin{array}{c}-1.00(-3.23,1.23) \\
\operatorname{Ref} \\
-1.05(-3.24,1.14)\end{array}$ & 0.53 \\
\hline
\end{tabular}

Patient- and centre-level characteristics were included in the multivariable analyses if they had $P$ values $<0.2$ in univariable analyses.

The coefficients reported in this table are unstandardised coefficients.

† Indigenous Australian refers to Aboriginal and Torres Strait Islander

$\ddagger$ Centre size and proportion of prevalent dialysis patients on home therapies were subcategorized into quartiles, with the second and third quartiles merged to become the reference category. Values defining quartiles are expressed for in-centre/home haemodialysis.

$95 \% \mathrm{Cl}=95 \%$ confidence interval; $\mathrm{AVF} / \mathrm{AVG}$ = arteriovenous fistula/arteriovenous graft; $\mathrm{HD}=$ haemodialysis; Ref = reference.

This article is protected by copyright. All rights reserved. 

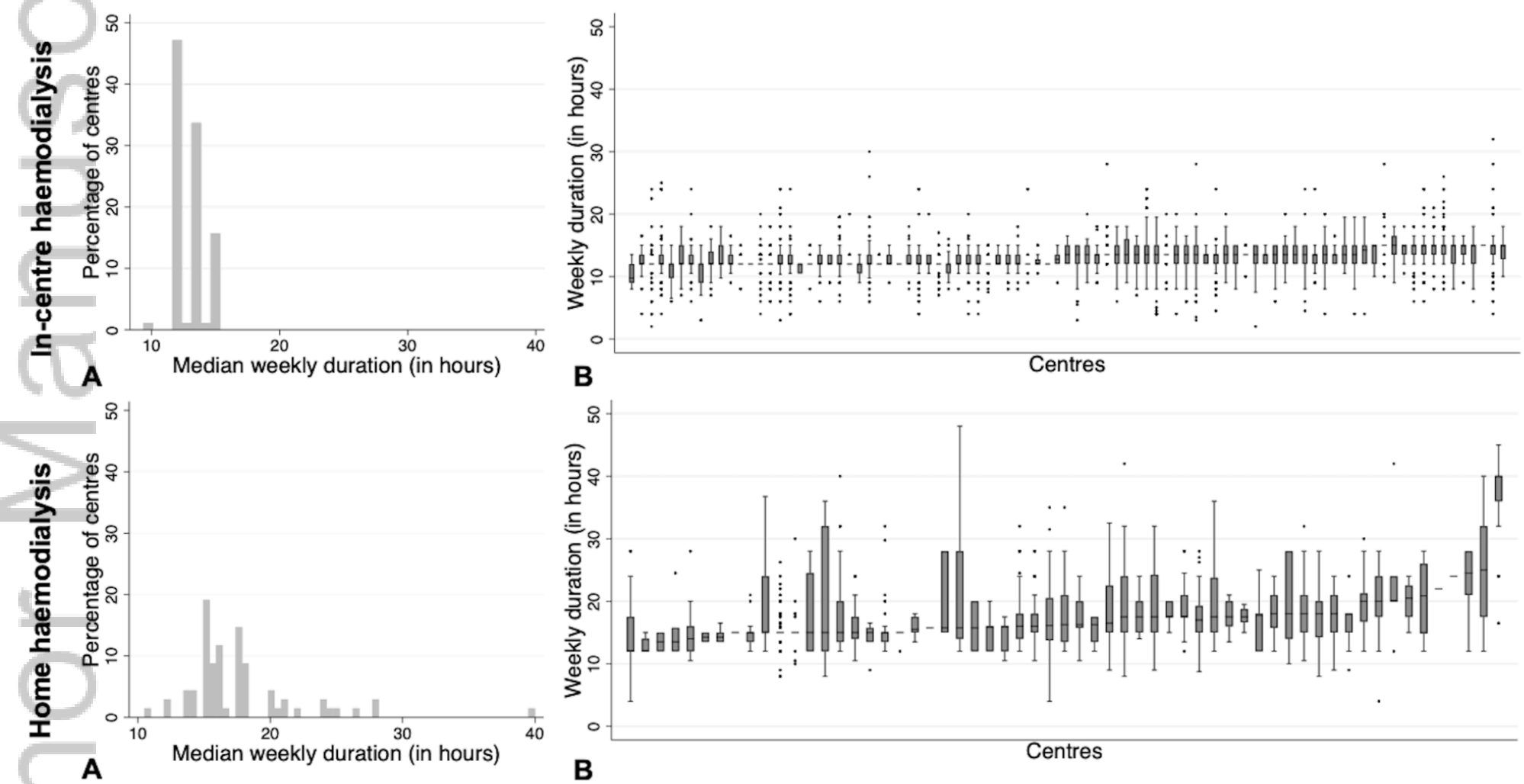

NEP_13782_Fig1_HighRes.tiff

This article is protected by copyright. All rights reserved. 


\section{In-centre haemodialysis}

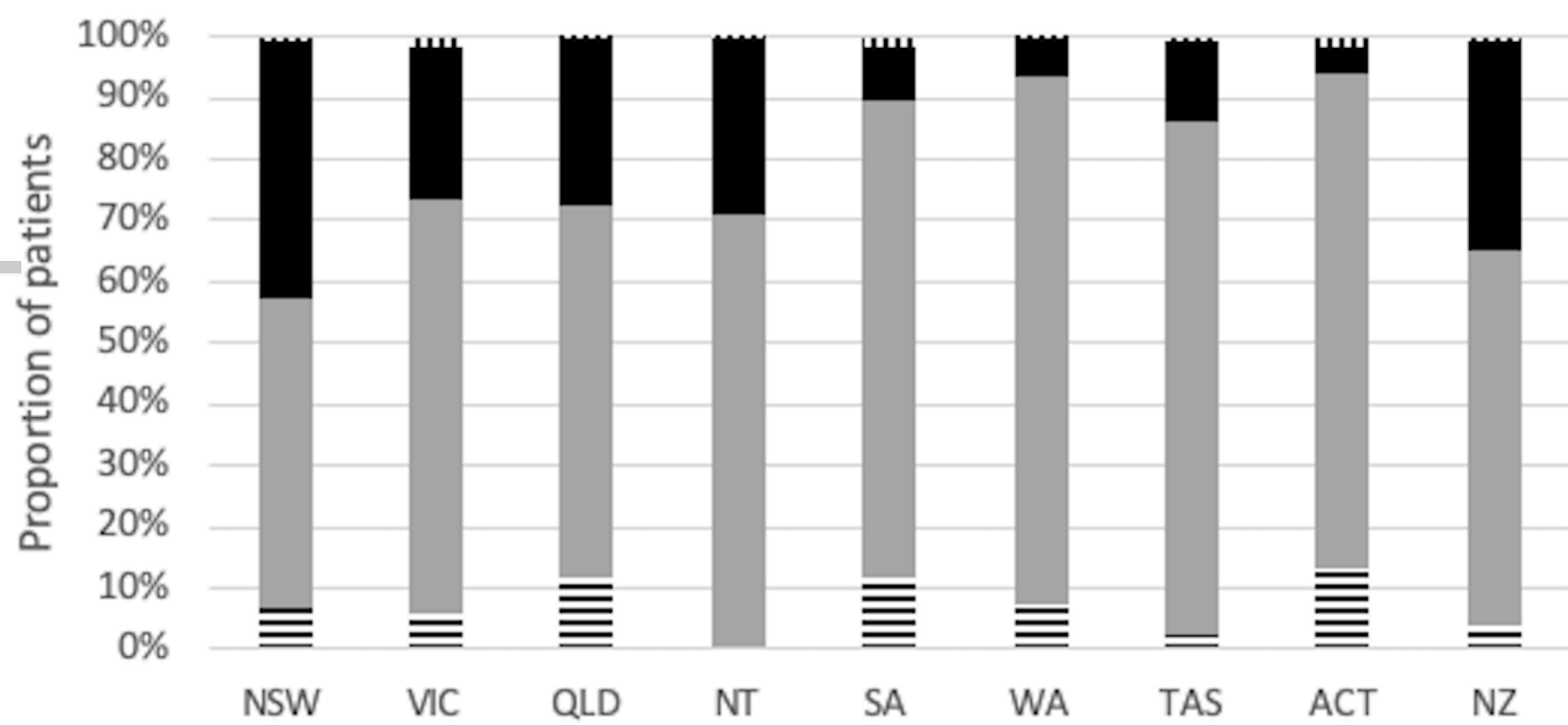
A
$=<12$ hours
a $12-<15$ hours
a $15-<20$ hours
II 20+ hours

\section{Home haemodialysis}

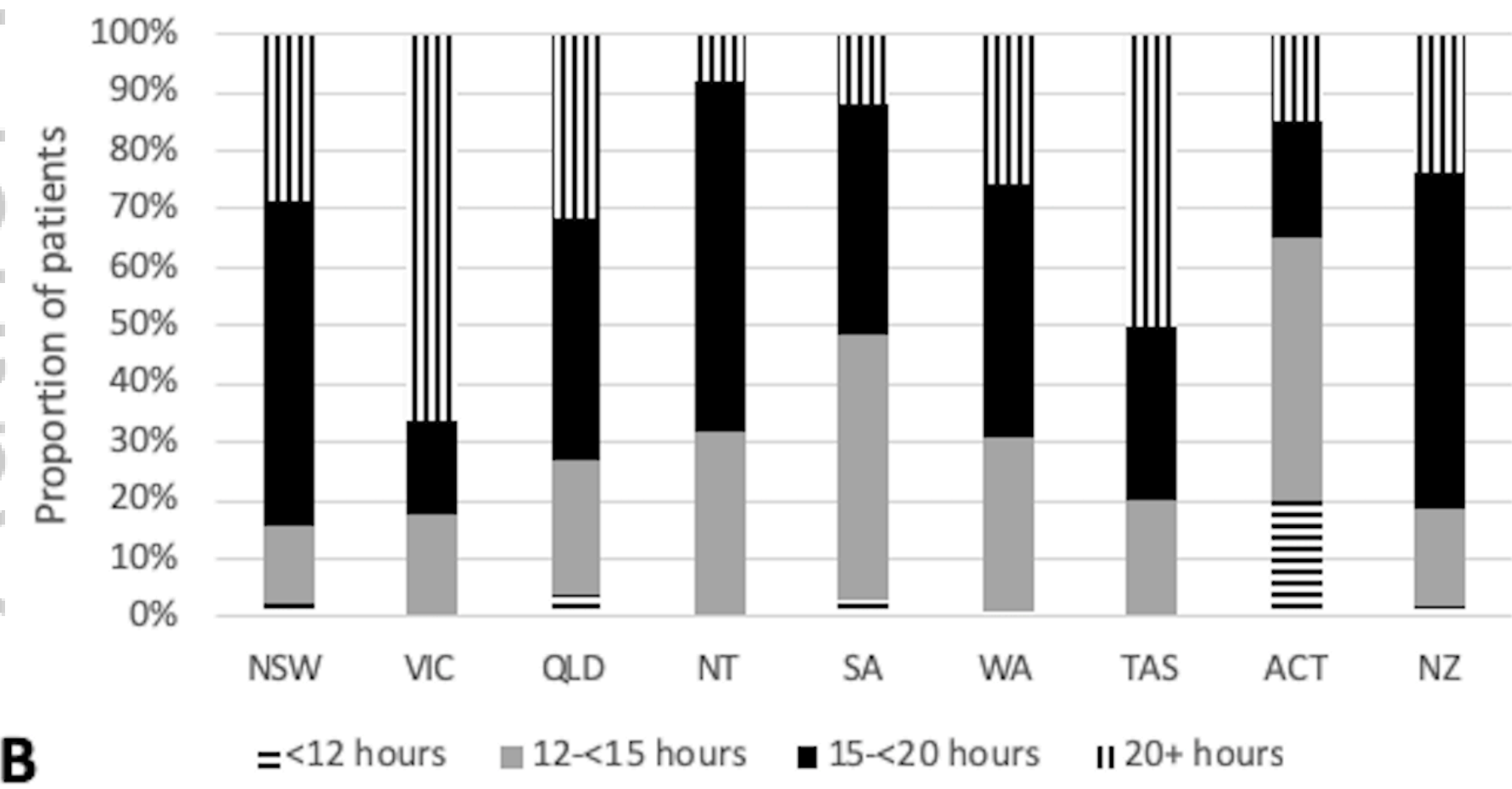

NEP_13782_Fig2_HighRes.tiff

This article is protected by copyright. All rights reserved. 


\section{In-centre haemodialysis}
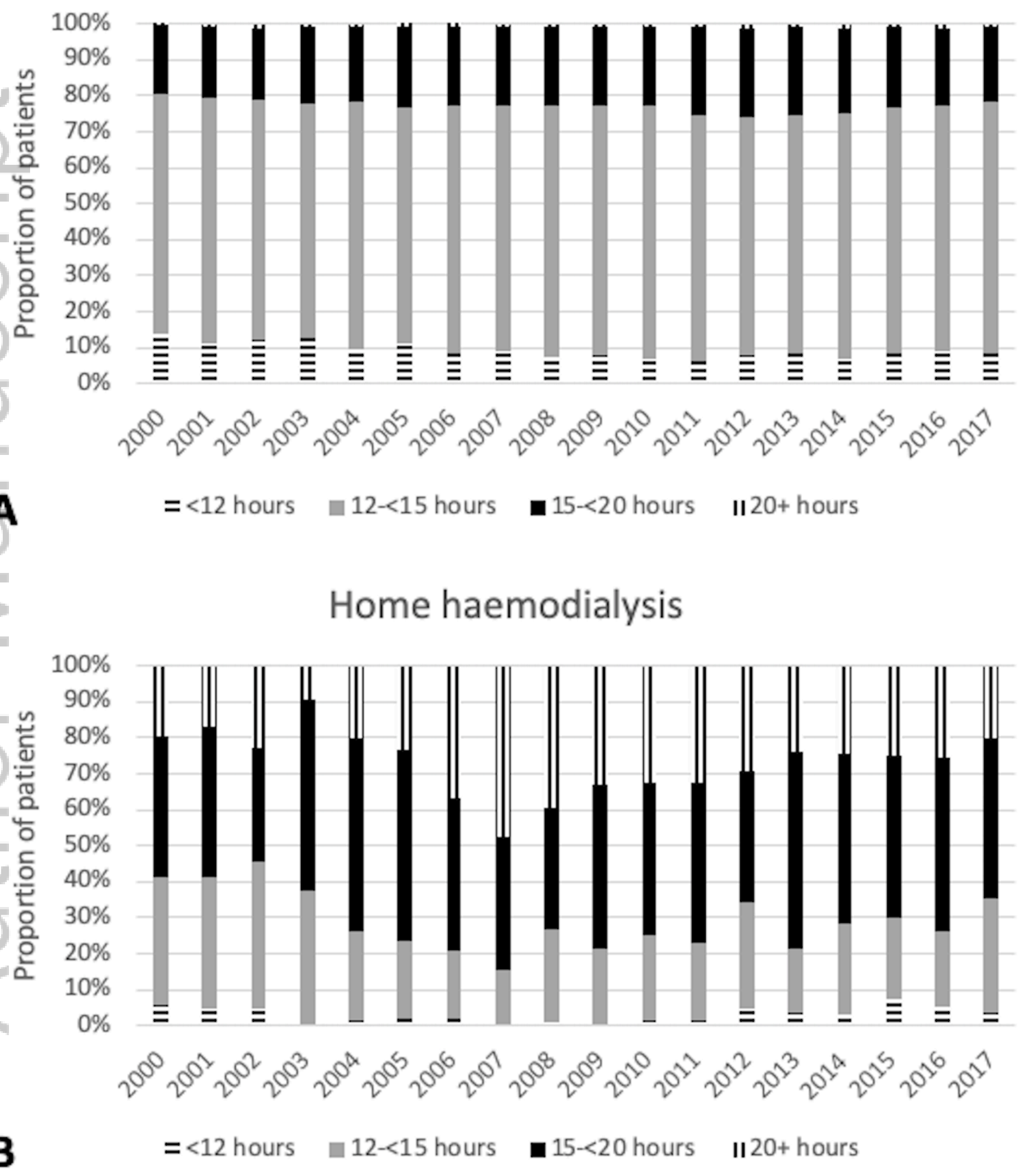

NEP_13782_Fig3_HighRes.tiff

This article is protected by copyright. All rights reserved. 


\section{University Library}

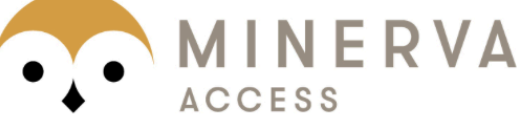

A gateway to Melbourne's research publications

Minerva Access is the Institutional Repository of The University of Melbourne

Author/s:

Ethier, I;Cho, Y;Davies, CE;Hawley, CM;Campbell, SB;Isbel, NM;Pascoe, EM;Polkinghorne,

KR;Roberts, M;See, EJ;Semple, D;van Eps, C;Viecelli, AK;Johnson, DW

Title:

Variability and trends over time and across centres in haemodialysis weekly duration in Australia and New Zealand

Date:

2020-10-22

Citation:

Ethier, I., Cho, Y., Davies, C. E., Hawley, C. M., Campbell, S. B., Isbel, N. M., Pascoe, E. M., Polkinghorne, K. R., Roberts, M., See, E. J., Semple, D., van Eps, C., Viecelli, A. K. \& Johnson, D. W. (2020). Variability and trends over time and across centres in haemodialysis weekly duration in Australia and New Zealand. NEPHROLOGY, 26 (2), pp.153-163. https:// doi.org/10.1111/nep.13782.

Persistent Link:

http://hdl.handle.net/11343/276471 